\title{
Obesity, school obesity prevalence, and adolescent childbearing among U.S. young women
}

\author{
Jennifer B. Kane ${ }^{a,{ }^{*}}$ and Michelle L. Frisco ${ }^{b}$ \\ ${ }^{a}$ Carolina Population Center, University of North Carolina at Chapel Hill, 123 W. Franklin Street, \\ Chapel Hill, NC 27516, USA \\ bDepartment of Sociology and The Population Research Institute, The Pennsylvania State \\ University, 413 Oswald Tower, University Park, PA 16802, USA
}

\section{Abstract}

In the United States, adolescent obesity reduces young women's odds of forming romantic and sexual partnerships but increases the likelihood of risky sexual behavior when partnerships occur. This led us to conduct a study examining the relationship between adolescent obesity and adolescent childbearing. Our study has two aims. We draw from prior research to develop and test competing hypotheses about the association between adolescent obesity and young women's risk of an adolescent birth. Drawing from risk regulation theory, we also examine whether the association between obesity and young women's risk of an adolescent birth may vary across high schools with different proportions of obese adolescents. Multilevel logistic regression models are used to analyze data from 4242 female students in 102 U.S. high schools who participated in Wave I (1994-1995) of the National Longitudinal Study of Adolescent Health. Results are the first to show that obesity reduces female adolescents' odds of childbearing, but that this association is not uniform across schools with different proportions of obese students. As the obesity prevalence in a school increases, so do obese young women's odds of childbearing. We conclude that understanding whether and how obesity is associated with young women's odds of having an adolescent birth requires attention to the weight context of high schools.

\section{Keywords}

Obesity; Adolescents; Childbearing; Secondary schools; BMI; National Longitudinal Study of Adolescent; Health; USA

\section{Introduction}

The most recent estimates indicate that more than half of all American adolescents are overweight and 19\% are obese (Ogden, Carroll, Curtin, Lamb, \& Flegal, 2010), making obesity one of the most significant public health problems facing U.S. adolescents, who are otherwise relatively healthy. Obesity's negative consequences for young people's health are well-documented (Daniels, 2006; IOM, 2006), as are its educational (Crosnoe, 2007), economic (Gortmaker, Must, Perrin, Sobol, \& Dietz, 1993), and social consequences (Cawley, Joyner, \& Sobal, 2006; Crandall \& Schiffhauer, 1998; Eisenberg, NeumarkSztainer, \& Story, 2003; Frank, Mueller, \& Crosnoe, 2008; Needham \& Crosnoe, 2005) that result from it being a highly stigmatized social status (Puhl \& Latner, 2007).

(c) 2013 Elsevier Ltd. All rights reserved.

*Corresponding author. Tel.: +1 919843 6257; fax: +1 919966 6638. jbkane@ unc.edu (J.B. Kane). 
Missing from the literature on consequences of adolescent obesity is an investigation of its association with adolescent childbearing. This omission may reflect evidence of obese young women's reduced odds of sexual and romantic partnership (Averett, Corman, \& Reichman, 2013; Cawley et al., 2006). A logical extension of this finding is that the lack of opportunity to become pregnant makes obese young women unlikely candidates for adolescent births. Unfortunately, recent evidence also suggests that obese young women with sexual partners engage in various risky sexual behaviors (Averett et al., 2013), some of which increase their vulnerability to pregnancy (Ratcliff, Jenkins, Reiter-Purtill, Noll, \& Zeller, 2011; Villers, Swanson, Savage, \& Korte, 2010). Thus, it is unclear whether a negative association between adolescent obesity and childbearing should be assumed.

This prompted the current study, which examines whether and how obesity influences young women's risk of adolescent child-bearing. We have two aims. We develop and test competing hypotheses about the association between obesity and female high school students' odds of an adolescent birth. Motivated by risk regulation theory (Glass \& McAtee, 2006), we also evaluate whether the association between obesity and female high school students' likelihood of childbearing varies across schools with different proportions of obese students. To our knowledge, this is the first study to investigate whether there is a relationship between young women's body weight and their risk of adolescent childbearing, and whether the schools they attend shape this association.

\section{Background}

\section{High school obesity and childbearing}

Most research on weight and fertility has been conducted by clinical and public health scholars. It focuses almost exclusively on adults and generally highlights the biological mechanisms that interfere with women's ability to conceive, carry pregnancies to term, and respond to infertility treatment (see Metwally, Li, \& Ledger, 2007 for a review). This research is motivated by the problematic nature of adult infecundity and infertility associated with obesity.

Obesity's consequences for adolescent childbearing are generally ignored, most likely because scholars, clinicians, and policy makers view adolescent births as negative, off-time life course events with deleterious consequences for young women and their children. If obesity reduces the likelihood of teenage childbearing, this is not necessarily a cause for concern from either a reproductive or public health perspective.

On the surface, hypothesizing a negative association between obesity and adolescent childbearing is intuitive. As noted previously, obesity impedes adolescent romantic and sexual partnerships (i.e., the opportunity to become pregnant) (Cawley et al., 2006) and adult women's physiological capacity for childbearing (Metwally et al., 2007).

Unfortunately, there is also evidence supporting competing hypotheses. Obesity could be positively associated with adolescent childbearing. Obese female adolescents with sexual partners engage in behavior that increases their risk of unintended births. They lack sexual decision-making power in romantic relationships (Wingood, DiClemente, Harrington, \& Davies, 2002), and compared with non-obese peers, they are more likely to use drugs and alcohol prior to sex (Ratcliff et al., 2011), have more partners, and have sex without contraception (Eisenberg, Neumark-Sztainer, \& Lust, 2005; Eisenberg et al., 2003; Villers et al., 2010). Unintended births are also higher among adolescents (versus adults) in general (Finer, 2010). There may also be no association between adolescent obesity and childbearing. The reduced likelihood of romantic and sexual partnership among obese adolescent women and their risky sexual behavior may cancel each other out. 
This prompted us to examine obese female adolescents' likelihood of childbearing and whether it could be one more health and social risk tied to adolescent obesity. Our analysis focuses on U.S. female high school students for three reasons. High school pregnancies ending in live births disrupt young women's educational attainment trajectories (Frisco, 2008; Steward, Farkas, \& Bingenheimer, 2009) and have deleterious health and social consequences for teen mothers and their children (Hofferth \& Reid, 2002; Hoffman \& Maynard, 2008). High schools are also sound targets for interventions aimed at curbing adolescent births because all states have laws requiring compulsory schooling until age 16 and two thirds require attendance until age 17 or 18 (Snyder \& Dillow, 2011). Finally, we can examine whether contextual features of high schools influence the association between body weight and childbearing.

High schools do more than educate adolescents. Because adolescents spend more time in schools than in any other social institution outside of the family (Dornbusch, 1989), schools also shape adolescent peer social cultures, and as a result, students' social interactions, friendships, romantic relationships (Crosnoe \& Muller, 2004; Kreager \& Haynie, 2011), and timing of sexual initiation (Teitler \& Weiss, 2000).

Research has begun to demonstrate that the proportion of obese students in schools is particularly influential and shapes academic and non-academic outcomes (Crosnoe \& Muller, 2004; Mueller, Pearson, Muller, Frank, \& Turner, 2010). To our knowledge, studies have not examined whether the proportion of obese adolescents in schools influences young women's risk of adolescent childbearing. This is a central study contribution.

We do not expect the proportion of obese students in a high school to directly influence female students' likelihood of child-bearing (although we test this supposition). Instead, we hypothesize that the proportion of obese students in a school may modify the association between adolescent obesity and childbearing.

This hypothesis stems from risk regulation theory (Glass \& McAtee, 2006), which recognizes that characteristics of social and built environments such as schools, make important contributions to individuals' behaviors. Unlike other ecological theories, features of social environments are not viewed as direct causes of individual behavior (supporting our supposition that the proportion of obese students in a high school will not directly influence adolescent childbearing). Instead, these characteristics are risk regulators that promote or constrain behaviors according to the realities of day-today life (Glass \& McAtee, 2006).

Applied to our study, the proportion of obese students within a school should be a risk regulator that conditions obese female students' likelihood of having an adolescent birth.

High schools are social institutions that include a fixed population of students who comprise an easily accessible pool of potential romantic and sexual partners for young people attending them. Partner selection within pools of potential mates tends to be based on homogamy, meaning that individuals tend to choose partners with similar physical and social characteristics (Blackwell \& Lichter, 2004; Carver, Joyner, \& Udry, 2003), including body weight (Carmalt, 2009). As a result, obese young women should have fewer constraints for child-bearing in schools with more obese students because they have more opportunities to find a same-weight partner and to engage in high-risk sexual behavior associated with obesity (Eisenberg et al., 2005, 2003; Villers et al., 2010). Thus, obese young women's risk of childbearing should increase as the proportion of obese students in their school increases. 


\section{Current study}

In summary, we examine the association between adolescent obesity and childbearing among female high school students and whether their odds of childbearing depend on the proportion of obese students in their high schools. We do so by analyzing data from the National Longitudinal Study of Adolescent Health (Add Health). This study makes important contributions to knowledge about young women's body weight and their reproductive behavior. Results will indicate whether it is safe to assume that the negative association between obesity and childbearing that has been documented among adult women is similarly observed among adolescents. Findings will also show whether fully understanding obese young women's risk of childbearing requires scholarship that pays attention to social contexts that differentially facilitate obese young women's opportunities for sexual partnership.

The United States has the highest teen birth rate of all industrialized nations-in some cases as high as nine times greater than other industrialized nations (Centers for Disease Control, 2010; Hamilton, Martin, \& Ventura, 2011; Singh \& Darroch, 2000). The detrimental health and social consequences of teen births for young women and their children are well documented (Centers for Disease Control, 2013) and motivated the President's 2010 Teen Pregnancy Prevention Initiative (TPPI) aimed at reducing teen pregnancies. Thus, understanding whether and under what circumstances obesity, a condition that impacts nearly one-fifth of all U.S. adolescent girls (Ogden, Carroll, Kit, \& Flegal, 2012), contributes to the risk of adolescent births is an important undertaking.

\section{Methods}

\section{Data and sample}

We analyze data from Add Health, a school-based, nationally representative sample of 20,745 7th-12th graders from 134 public, private, and parochial schools in 1994-1995 (Wave I). Respondents were followed up in 1996 (Wave II), 2001-2002 (Wave III), and 2008 (Wave IV) (Harris, 2011). We use data from the in-home interviews conducted during Waves I and III data collection efforts. Wave I data are used because this is the only wave when school-level characteristics were obtained. Furthermore, a significant proportion of Wave I respondents are not in their Wave I schools at later survey waves because of high school graduation and school transfers. Thus, we would lose a significant proportion of the Add Health sample and could not be sure that students' school-level characteristics were applicable to their current school if we did not rely on Wave I data as our baseline. Wave III data allow for complete construction of pregnancy and birth histories during high school.

Our sample includes 8015 female participants in both Waves I and III. We exclude young men because adolescent childbearing burdens fall more heavily on young women, and young men's reports of nonmarital parenthood are unreliable (Upchurch, Lillard, Aneshensel, \& Li, 2002). We only include Wave I female high school students in grades 912 who were 19 years old or younger $(N=5582)$. In cases where an Add Health school included grades traditionally associated with junior high and high school, we retained these schools in the analysis and kept their female students in the analysis if they were in grades 9-12. In analyses excluding these students and schools, study findings were substantively and statistically similar to results shown here. We also include only women with no reported pregnancies or births prior to Wave I $(N=5363)$. This ensures proper causal ordering between obesity and childbearing. We also only include young women with valid sampling weights $(N=5110)$, in order to compare results across models adjusted and unadjusted for sampling weights (we return to this point below). Finally, our sample only includes young women who did not transfer high schools between Waves I and II $(N=4242)$. Because a 
primary study aim is examining how school weight context influences the association between obesity and adolescent childbearing, this constraint helps to ensure that our measure of the school obesity prevalence captures the school weight context of the high schools young women currently attend (Add Health respondents who transfer schools are followed, but we do not have data about the weight of students in their new schools). We replicated analyses in a sample including young women who transferred schools using models that controlled for transfer status. Results were substantively and statistically similar to those presented here.

Missing data on explanatory variables is minimal (2\%-4\% in most cases). There was no missing data on childbearing, because we analyze childbearing history data that we corrected using the same methods as previous research (Schoen, Landale, \& Daniels, 2007). We also replicated our results using the revised childbirth history data collected in Wave IV of Add Health. We use a single imputation procedure (impute in Stata 12.0) to replace missing data on all independent variables because listwise deletion can produce biased estimates even when missing data are minimal and "missing at random" (Acock, 2005). Supplementary analyses suggest that findings obtained from analyzing imputed and unimputed data are substantively and statistically similar.

\section{Measures}

Adolescent childbearing-We use Wave III data to construct a dichotomous indicator of whether young women had a high school pregnancy ending in a live birth ( $1=$ yes). For simplicity, we refer to our dependent variable as adolescent childbearing in the remainder of the text. We focus on childbearing rather than pregnancy because child-bearing reshapes women's lives more than pregnancy, often posing negative consequences for both mothers (Frisco, 2008; Steward et al., 2009) and their children (Hofferth \& Reid, 2002). Pregnancy is also more difficult to reliably measure because young women underreport pregnancies terminated by choice or spontaneously before pregnancy is recognized (Jones \& Forrest, 1992). In supplementary analyses, we estimated models predicting pregnancies rather than births and found comparable results.

Obesity-Obesity is operationalized using young women's Wave I self-reported height and weight. While interviewer-measured height and weight data are preferable due to bias inherent in self-reported height and weight (Brener, Eaton, Lowry, \& McManus, 2004), Wave I only contains self-reported measures. Fortunately, self-reported and measured height and weight data are quite consistent. In Wave II of Add Health, 96\% of respondents are consistently classified as obese using self-reported and measured height and weight data (Goodman, Hinden, \& Khandelwal, 2000). Therefore, using Wave I self-reported data likely introduces very little bias into our analysis. In addition, because young women tend to under-report weight, our use of self-reported data likely lead to more conservative estimates of associations between obesity and adolescent childbearing.

We use Centers for Disease Control and Prevention (CDC) (2000) guidelines to first construct age and sex specific BMI percentiles from self-reported height and weight and then to create a dichotomous indicator of obesity (BMI $\geq 95$ th percentile $=1$ ). To ensure the sensitivity of study results to this specification of body weight, we conducted two sets of supplementary analyses. The first set utilized IOTF cut-offs to operationalize obesity. Results from these models were substantively and statistically similar to those presented here. The second set estimated whether being overweight or obese $($ BMI $\geq 85$ th percentile $=$ 1) was associated with adolescent childbearing. It was not, even in a bivariate regression model $(b=0.07 ; \mathrm{SE}=0.23 ; p=.77)$. 
Proportion of obese students within a high school-This variable was constructed by aggregating individual-level data obtained from the Wave I in-home survey (for both male and female students) up to the school-level prior to applying sample constraints.

Control variables-Several Wave 1 individual- and school-level variables serve as control variables because they may confound associations between high school obesity, the proportion of obese students in schools, and childbearing. We treat all variables only as confounders and none as possible mechanisms because all control variables are measured at the same time point as obesity and the school-level obesity prevalence.

Individual-level controls include Wave I age, race-ethnicity (non-Hispanic Black, Hispanic, non-Hispanic other, and the reference category, non-Hispanic White), household incomeneeds ratio (based on measures of household income and number of persons in the household at Wave I), single mother household ( $1=$ yes), and resident parent(s) high school dropout status $(1=$ one or both parents dropped out, $0=$ neither parent dropped out). Models also control for respondents' high school dropout status $(1=$ yes $)$, sexual initiation $(1=$ reported sexual intercourse before Wave I), number of sexual partners, and age at menarche - a proxy for when respondents' biological capacity to reproduce begins. Self-esteem, weight perceptions, and physical attractiveness are also controlled. Self-esteem is based on four questions asking if respondents like themselves the way they are, feel socially accepted, feel loved and wanted, and are physically fit ( $1=$ strongly agree, $5=$ strongly disagree). We sum question responses and compute an average value. Weight perceptions ask how respondents think of themselves in terms of weight: very underweight, slightly underweight, about the right weight (reference), slightly overweight, or very overweight. Following prior research (Frisco, Houle, \& Martin, 2009), we combine very underweight and slightly underweight into one category and very overweight and slightly overweight into one category. Also similar to previous research (Halpern, Waller, Spriggs, \& Hallfors, 2006), interviewer-rated physical attractiveness, captured on scale of 1 (very unattractive) to 5 (very attractive), is controlled.

School-level control variables include the schools' average income-needs ratio (the incomeneeds ratio averaged across all respondents in a given school), racial composition, urbanicity, region, average student achievement (percent of students who test below grade level, average grade point average), and peer social context (percent of students who participate in school sports). All variables were constructed by aggregating each respective individual-level variable (from the full Wave 1 in-home sample) up to the school-level except for urbanicity and region, which were reported by school administrators.

\section{Statistical analyses}

We first describe our sample by presenting descriptive statistics for all analytic variables in Table 1. They show how well our sample represents U.S. female high school students.

We then estimate multilevel logistic regression models to estimate young women's odds of adolescent childbearing using the xtmelogit command in Stata v12. This method is appropriate in studies like ours where individuals (level-1) are nested in schools (level-2). As the xtmelogit command does not accommodate sample weighting, we replicated our analyses with and without sampling weights in HLM 7.0. The associations between obesity, school-level obesity prevalence and the risk of adolescent childbearing were substantively and statistically similar to estimates presented here.

We checked a basic model assumption - that level-1 variables do not vary across level-2 units using recommended diagnostic tests (Raudenbush \& Bryk, 2002). Results indicated 
that including random coefficients did not significantly improve model fit, which suggests that multilevel models using random intercepts are appropriate for our study.

All continuous variables in multilevel models are grand mean-centered. When we do not grand mean-center variables, our results are equivalent to those presented here with respect to residual values, predicted values, and model fit. The advantage of grand mean-centering is that it (a) accommodates a simpler interpretation of the intercept $\left(\mathrm{Y}_{00}\right)$ and (b) reduces the potential for multicollinearity when cross-level interactions are entered into statistical models (Kreft \& De Leeuw, 1998).

We present a series of six statistical models. Models 1 and 2 include individual-level covariates only. Model 1 only includes obesity; Model 2 adds all other individual-level covariates to assess whether any association between obesity and adolescent childbearing observed in Model 1 is robust to adjusting results for these confounders. The next two models only include school-level variables. Model 3 includes only the proportion of obese students within a school and Model 4 adds all other school-level covariates. Model 5 includes all individual-level and school-level covariates, demonstrating how individual-level weight and the proportion of obese students within a high school are associated with young women's odds of adolescent childbearing net of all confounders. Finally, Model 6 includes all covariates from Model 5 and a cross-level interaction between obesity and the proportion of obese students in young women's high schools to estimate whether the relationship between obesity and adolescent child-bearing varies with the proportion of obese students in a high school.

For each model, we present odds ratios and an estimate of tau. We compare the value of tau for a null model (including no predictors) with the value of tau for Models 1 through 6 (described above) using the formula, $\left(\left(T_{\text {null }}-T_{\text {model }}\right) T_{\text {null }}\right)$. This allows us to demonstrate the amount of between-school variance in high school childbearing that is explained by the covariates in each model. For reference, the value of tau in the null model (shown in the note below Table 2) is 0.31 .

\section{Results}

Panel A in Table 1 shows the sample's characteristics. Only $4.9 \%$ of young women had a high school pregnancy that ended in a live birth. Roughly $9.4 \%$ of the sample was obese at Wave I, which is comparable to National Health and Nutrition Examination Survey (NHANES) estimates of the female adolescent obesity prevalence at the time when Add Health Wave I data were collected in 1994- 1995 (9.7\%) (Ogden \& Carroll, 2010). The sample's sociodemographic characteristics mirror those of U.S. high school students in the mid-1990s (Green et al., 1995). More than half of the sample is non-Hispanic White (58.5\%), compared with $16.0 \%$ non-Hispanic Black, $19.6 \%$ Hispanic and $6.0 \%$ nonHispanic other. Roughly one fifth of sample members lived in a single mother household $(18.8 \%)$ and had at least one parent who did not complete high school (18.7\%). Respondents were, on average, 16 years old at Wave I and lived in households where the total income exceeded the federal poverty line adjusted for household size (>1.0).

Estimates in Table 1 also show that $39.8 \%$ of respondents had initiated sex by Wave I, their number of sexual partners is low, and their average age at menarche was 12.7. The sample also has relatively high self-esteem, but a substantial proportion of young women perceive being overweight (39.8\%) despite being rated as relatively attractive by interviewers. One tenth of respondents dropped or stopped out of high school (10.5\%). Estimates in the Appendix A indicate that obese and non-obese respondents are not similar with respect to several key variables_-including childbearing. 
Panel B in Table 1 describes the high schools sample members attend. There is substantial variation in the proportion of obese students within schools. Most important for our study, only $1.5 \%$ of students in the leanest schools are obese while $26.3 \%$ of students in the heaviest schools are obese. On average, across schools, $10.7 \%$ of students are obese.

Table 2 presents estimates from multilevel logistic regression models predicting adolescent childbearing. Model 1 indicates that obesity reduces the estimated odds of childbearing by $44 \%(1-0.56 \times 100)$. When we include all individual-level control variables in Model 2, obese young women still have lower odds of childbearing than their non-obese peers, suggesting that the negative association between obesity and adolescent childbearing is not due to confounders.

Model 3 evaluates whether the proportion of obese students in a school is associated with female students' likelihood of child-bearing. It shows that a female student's odds of an adolescent birth increase as the proportion of obese students in her high school increases. However, Model 4 shows that this is a function of other school-level covariates. Supplementary analyses (not shown) indicated that controlling for both the schools' average income-needs ratios and racial composition explains this finding. Comparing tau values in the null model and model $4((0.31-0.14) / 0.31)$ indicates that including all school-level covariates in Model 4 explains 55\% of the between-school variance in high school childbearing in this sample. Tau is also no longer statistically significant in Model 4 which signifies that there is no longer significant between-school variation in high school childbearing present.

In Model 5, which includes all individual-level and school-level covariates, obese female students continue to have significantly reduced odds of childbearing and the negative estimated effect of being obese is substantively and statistically similar to estimates from Models 1 and 2. That said, the statistically significant cross-level interaction between obesity and the proportion of obese students in high school that is included in Model 6 indicates that obese female students' odds of childbearing increase as the proportion of obese students in their school increases. Note that this estimated effect is robust to the inclusion of a wide range of individual- and school-level confounders in Model 6. A likelihood ratio test showed that Model 6 fits the data better than Model $5(p<.05)$. The full set of covariates in Model 6 also explains 97\% of the between-school variance in high school childbearing (relative to the null model).

Fig. 1 depicts findings from Model 6 graphically. It shows the predicted probability of childbearing for all young women (dotted gray line, shown for reference), non-obese young women (dotted black line), and obese young women (solid black line) as the proportion of obese students in high schools increases. Predicted probabilities were calculated by holding all individual-level and school-level confounders in Model 6 constant at their mean or modal values. This is a useful way to show the meaning of a cross-level interaction because it depicts the estimated effect of a level-one variable at different points along the distribution of a level-two variable (Finch et al., 2010).

The figure shows that the association between obesity and the predicted probability of high school childbearing is conditioned by a school's obesity prevalence. The values portrayed at the lower end of the graph suggest that, in leaner schools, the probability of childbearing is stratified by obesity status such that non-obese young women are at greater risk than obese young women. In schools in which around $17 \%$ of students are obese, the probability of childbearing is no different for these two subgroups of women. In the heaviest schools (those in which more than $17 \%$ of students are obese), we observe the converse association: 
the probability of childbearing is again stratified, but here we see obese young women at greater risk of childbearing than their non-obese counterparts.

Recall that findings depicted in Fig. 1 are net of a wide range of individual- and school-level control variables, suggesting that study findings are quite robust. To further ensure the robustness of the statistically significant cross-level interaction in Model 6, we estimated seven supplementary models using Stata's xtmelogit command (available upon request) that added an additional cross-level interaction term between obesity and each school-level covariate to Model 6, one at a time. In these models, the relative size and significance of the cross-level interaction between obesity and the proportion of obese students was largely unchanged. In addition, none of the added cross-level interactions were statistically significant. This adds further evidence that it is a school's weight context, and not some other characteristic of schools, that influences the association between obesity and women's odds of adolescent childbearing.

\section{Discussion}

This study examined whether obesity was associated with childbearing among female high school students and whether this association varied across schools with different proportions of obese students. It is the first study that has developed and tested suppositions about the relationship between obesity and adolescent childbearing generally, and specifically across schools where the prevalence of obesity varied. We focused on this feature of school context because previous research on adolescent mate selection suggested that it should shape obese young women's ability to form romantic and sexual partnerships.

Prior research led us to propose three competing hypotheses about the basic association between obesity and adolescent child-bearing. We found support for a negative association. Obesity reduced the estimated odds of childbearing among female high school students net of individual-level and school-level con-founders. This is consistent with and builds on prior research suggesting that obesity reduces romantic and sexual partnership among adolescents (Cawley et al., 2006). Study findings also extended clinical literature about obesity's negative association with childbearing by showing that this relationship is not just evident for adult women.

Risk regulation theory (Glass \& McAtee, 2006) led us to hypothesize that this basic finding may not fully capture when and how obesity influenced female high school students' risk of an adolescent birth. Instead, Glass and McAtee's (2006) framework led us to posit that obese young women's odds of childbearing may increase as the proportion of obese students in a school increased because they would have more opportunities to enter into partnerships that were homogamous with respect to body weight. As a result, obese young women should have more opportunities to engage in the high-risk sexual behavior associated with being an obese adolescent (Eisenberg et al., 2005, 2003; Ratcliff et al., 2011; Villers et al., 2010).

Study results supported this premise. The proportion of obese students enrolled in school did not directly influence female high school students' odds of childbearing once statistical models were adjusted for confounders, but obesity's association with adolescent childbearing did vary with the proportion of obese students within high schools. In leaner schools (in this study, schools where less than $17 \%$ of students were obese), non-obese young women were at greater risk of childbearing than obese young women. Conversely, obese young women exhibited a greater risk of childbearing than non-obese young women in heavier schools (or, those were more than $17 \%$ of students were obese).

Study findings make several important contributions to the literature. Most generally, the study was the first to show that a high school's obesity prevalence plays a significant role in 
shaping the association between obesity and adolescent childbearing. In addition, results suggested that risk regulation theory (Glass \& McAtee, 2006) is applicable to studies aimed at investigating how risk factors for behavioral outcomes such as adolescent child-bearing are contingent upon social context. Results also added to a burgeoning body of research that shows how obesity influences outcomes associated with adolescents' reproductive health and that its impact is not the same across outcomes or contexts (Averett et al., 2013; Eisenberg et al., 2005, 2003; Villers et al., 2010). Finally, our study results, along with recently published research showing that obesity is not similarly related to childbearing among different cohorts of women (Frisco, Weden, Lippert, \& Burnett, 2012), also suggested that social context has a significant role in shaping the association between women's body weight and childbearing. Together, this study and the one just cited suggest that the negative association between obesity and childbearing is not solely due to women's biological capacity to reproduce. If this were the case, obesity would not have different consequences for childbearing in different school contexts or historical settings. Future research should examine other contexts that lead obesity to be more and less consequential for childbearing and other health and social outcomes.

Future research should also more explicitly analyze the role that partnership dynamics play in the associations observed in this study by testing whether obesity differentially influences the odds of dating and participating in risky sexual behavior (e.g. frequency of sexual intercourse, proportion of intercourse that occur without contraception) across schools with different proportions of obese students. This analysis was beyond the scope of the current study. It would also be fruitful to examine whether obesity's consequences for adolescent childbearing are not the same for young women with different background characteristics.

Findings should be considered within the context of study limitations. Results are only generalizable to high school students, not necessarily to younger women or those not attending high schools. We focused on this population because it allowed us to examine high schools as an important social context shaping adolescent childbearing. High schools can also play an important role in curbing U.S. teen pregnancies, which are consistently higher than those in most other developed nations (Centers for Disease Control, 2010; Hamilton et al., 2011; Singh \& Darroch, 2000). This was therefore a purposeful aspect of the study's design.

Second, analyses used an obesity measure constructed from self-reported height and weight data so that obesity and school weight context could be measured at the same time point. These data may be biased because overweight and obese young women tend to under-report weight (Elgar, Roberts, Tudor-Smith, \& Moore, 2005). That said, national estimates of the obesity prevalence from NHANES were relatively consistent with the obesity prevalence among our female sample. If some bias is still evident, it should have led us to underestimate obesity's association with childbearing.

Third, we did not test the mechanisms explaining associations between obesity, school obesity prevalence, and childbearing among female high school students. Future research should take this next step and may want to focus on factors such as the nature of young women's romantic and sexual relationships, power and control in these relationships, and contraceptive use. Finally, we did not fully address all possible confounders of the association between obesity and teen fertilityda limitation of all studies that analyze secondary data with non-experimental methods.

Key findings demonstrated complex associations between female high school student's weight, school obesity prevalence, and adolescent childbearing. On average, obesity reduced female students' risk of childbearing, but school context regulated this risk. Obese young 
women attending heavier schools are at greater risk of bearing children than their obese counterparts attending leaner schools. Targeted intervention programs aimed at curbing teen births should not ignore obese young women, especially in high schools where obesity is common. Similarly, school programs conveying obesity's negative consequences to young women should highlight the lack of agency and risky sexual behavior in relationships that they may be prone to, which could result in pregnancy and early childbearing. Given increases in the adolescent obesity prevalence since the time these data were collected for our sample (1994-1995) (Ogden et al., 2010), such school-level interventions may be even more important to the young women currently enrolled in U.S. high schools.

\section{Acknowledgments}

This research uses data from Add Health, a program project directed by Kathleen Mullan Harris and designed by J. Richard Udry, Peter S. Bearman, and Kathleen Mullan Harris at the University of North Carolina at Chapel Hill, and funded by grant P01-HD31921 from the Eunice Kennedy Shriver National Institute of Child Health and Human Development, with cooperative funding from 23 other federal agencies and foundations. Special acknowledgment is due Ronald R. Rindfuss and Barbara Entwisle for assistance in the original design. Information on how to obtain the Add Health data files is available on the Add Health website (http://www.cpc.unc.edu/addhealth). The first author gratefully acknowledges postdoctoral funding support from the Eunice Kennedy Shriver National Institute of Child Health and Human Development grant P01-HD31921 (PI: Kathleen Mullan Harris), grant T32 HD007168 (PI: CarolynT. Halpern), and grant R24 HD050924 (PI: S. Philip Morgan), along with pre-doctoral funding support from NICHD grant T-32HD007514 (PI: Valarie King) and grant 2R24HD041025-11 (PI: Jennifer Van Hook). The second author was supported by grant R01 HD40428-02 (PI: Gary Sandefur) and NICHD grant K 12HD055882 (PI: Carol Weisman). Opinions reflect those of the authors and not necessarily those of the granting agencies. The authors wish to thank Nan Astone, Molly Martin, Wayne Osgood, and Jenny Trinitapoli for their helpful comments on this manuscript.

\section{Appendix A. Characteristics of non-obese and obese sample members}

\begin{tabular}{|c|c|c|}
\hline \multirow[t]{2}{*}{ Characteristic } & \multicolumn{2}{|l|}{ Percent or mean } \\
\hline & Non-obese $(n=3850)$ & Obese $(n=392)$ \\
\hline High school childbearing (\%) & $5.0^{a}$ & 2.9 \\
\hline \multicolumn{3}{|l|}{$\begin{array}{l}\text { Sociodemographic } \\
\text { characteristics }\end{array}$} \\
\hline $\begin{array}{l}\text { Parent(s) did not complete } \\
\text { high school }(\%)\end{array}$ & 18.2 & 22.3 \\
\hline $\begin{array}{l}\text { Mean household } \\
\text { income-needs ratio } \\
\text { (range, } 0-83.7 \text { ) }\end{array}$ & $3.2^{a}(0.18)$ & $2.4(0.23)$ \\
\hline \multicolumn{3}{|l|}{ Race/ethnicity } \\
\hline Non-Hispanic Black (\%) & $14.3^{a}$ & 30.3 \\
\hline Hispanic $(\%)$ & 19.5 & 20.0 \\
\hline Non-Hispanic other (\%) & 6.2 & 2.1 \\
\hline $\begin{array}{l}\text { Non-Hispanic White (\%) } \\
\text { (reference) }\end{array}$ & $59.9^{a}$ & 47.6 \\
\hline Mean age (range, 13-21) & $16.3^{a}(0.03)$ & $16.3(0.13)$ \\
\hline $\begin{array}{l}\text { Single mother household (\%) } \\
\text { Other individual-level control } \\
\text { Variables }\end{array}$ & $17.9^{a}$ & 27.2 \\
\hline Sexual initiator $(\%)$ & $39.9^{a}$ & 36.5 \\
\hline $\begin{array}{l}\text { Mean number of sexual } \\
\text { partners (range, } 0-4 \text { ) }\end{array}$ & $0.8(0.05)$ & $0.8(0.11)$ \\
\hline $\begin{array}{l}\text { Mean age at first menses } \\
\text { (range, 7-26) }\end{array}$ & $12.8(0.06)$ & $12.6(0.23)$ \\
\hline
\end{tabular}




\begin{tabular}{lll}
\hline Characteristic & Percent or mean & \\
\cline { 2 - 3 } & Non-obese $(n=3850)$ & Obese $(n=392)$ \\
\hline $\begin{array}{l}\text { Mean self-esteem (range, } \\
1-5)\end{array}$ & $4.0^{a}(0.02)$ & $3.7(0.05)$ \\
Weight perceptions & & \\
Underweight (\%) & $12.3^{a}$ & 1.7 \\
Overweight (\%) & $34.7^{a}$ & 92.5 \\
$\begin{array}{l}\text { Just about the right } \\
\text { weight (\%) (reference) }\end{array}$ & $53.0^{a}$ & 5.8 \\
$\begin{array}{c}\text { Mean interviewer-rated } \\
\text { physical attractiveness } \\
\text { (range, 1-5) }\end{array}$ & $3.8^{a}(0.03)$ & $3.0(0.07)$ \\
$\begin{array}{c}\text { Dropped or stopped out } \\
\text { of high school (\%) }\end{array}$ & $10.0^{a}$ & 15.2 \\
\hline
\end{tabular}

Notes: Statistics are weighted. Standard errors are in shown in parentheses when appropriate.

${ }^{a}$ Denotes a significant difference between groups $(p<.10)$.

\section{References}

Acock AC. Working with missing values. Journal of Marriage and Family. 2005; 67(4):1012-1028.

Averett S, Corman H, Reichman NE. Effects of overweight on risky sexual behavior of adolescent girls. Economic Inquiry. 2013; 51(1):605-619.

Blackwell DL, Lichter DT. Homogamy among dating, cohabiting, and married couples. The Sociological Quarterly. 2004; 45(4):719-737.

Brener ND, Eaton DK, Lowry R, McManus T. The association between weight perception and BMI among high school students. Obesity. 2004; 12(11):1866-1874.

Carmalt J. Essays on assortative mating: Body weight, relationships, and health. 2009

Carver K, Joyner K, Udry JR. National estimates of adolescent romantic relationships. 2003

Cawley J, Joyner K, Sobal J. Size matters. Rationality and Society. 2006; 18(1):67.

Centers for Disease Control. CDC clinical growth charts. 2000. From. http://www.cdc.gov/ growthcharts/

Centers for Disease Control. Teen birth rates declined again in 2009. 2010. From. http://www.cdc.gov/ Features/dsTeenPregnancy/index.html

Centers for Disease Control. Preventing teen pregnancy in the US. 2013. From. http://www.cdc.gov/ vitalsigns/teenpregnancy/

Crandall CS, Schiffhauer KL. Anti-fat prejudice: beliefs, values, and American culture. Obesity Research. 1998; 6(6):458. [PubMed: 9845236]

Crosnoe R. Gender, obesity, and education. Sociology of Education. 2007; 80(3):241.

Crosnoe R, Muller C. Body mass index, academic achievement, and school context: examining the educational experiences of adolescents at risk of obesity. Journal of Health and Social Behavior. 2004; 45(4):393. [PubMed: 15869112]

Daniels SR. The consequences of childhood overweight and obesity. The Future of Children. 2006; 16(1):47-67. [PubMed: 16532658]

Dornbusch SM. The sociology of adolescence. Annual Review of Sociology. 1989; 15:233-259.

Eisenberg ME, Neumark-Sztainer D, Lust KD. Weight-related issues and high-risk sexual behaviors among college students. Journal of American College Health. 2005; 54(2):95-101. [PubMed: $16255321]$

Eisenberg ME, Neumark-Sztainer D, Story M. Associations of weight-based teasing and emotional well-being among adolescents. Archives of Pediatrics and Adolescent Medicine. 2003; 157(8): 733. [PubMed: 12912777] 
Elgar FJ, Roberts C, Tudor-Smith C, Moore L. Validity of self-reported height and weight and predictors of bias in adolescents. Journal of Adolescent Health. 2005; 37(5):371-375. [PubMed: 16227121]

Finch BK, Phuong Do D, Heron M, Bird C, Seeman T, Lurie N. Neighborhood effects on health: concentrated advantage and disadvantage. Health \& Place. 2010; 16(5):1058-1060. [PubMed: 20627796]

Finer LB. Unintended pregnancy among U.S. adolescents: accounting for sexual activity. Journal of Adolescent Health. 2010; 47(3):312-314. [PubMed: 20708573]

Frank K, Mueller AS, Crosnoe R. Gender, body size and social relations in American high schools. Social Forces. 2008; 86(3):1189-1216.

Frisco ML. Adolescents' sexual behavior and academic attainment. Sociology of Education. 2008; 81(3):284. [PubMed: 23745012]

Frisco ML, Houle JN, Martin MA. Adolescent weight and depressive symptoms: for whom is weight a burden? Social Science Quarterly. 2009; 90(4):1019-1038. [PubMed: 23585698]

Frisco ML, Weden MM, Lippert AM, Burnett KD. The multidimensional relationship between early adult body weight and women's child-bearing experiences. Social Science \& Medicine. 2012; 74(11):1703-1711. [PubMed: 21944717]

Glass TA, McAtee MJ. Behavioral science at the crossroads in public health: extending horizons, envisioning the future. Social Science \& Medicine. 2006; 62(7):1650-1671. [PubMed: 16198467]

Goodman E, Hinden BR, Khandelwal S. Accuracy of teen and parental reports of obesity and body mass index. Pediatrics. 2000; 106(1):52-58. [PubMed: 10878149]

Gortmaker SL, Must A, Perrin JM, Sobol AM, Dietz WH. Social and economic consequences of overweight in adolescence and young adulthood. New England Journal of Medicine. 1993; 329(14):1008-1012. [PubMed: 8366901]

Green, PJ.; Dugoni, BL.; Ingels, SJ.; Camburn, E.; Center National Opinion Research. Quinn, P., et al. A profile of the American high school senior in 1992 (NCES 95-384). Washington, D.C: National Center for Education Statistics; 1995.

Halpern CT, Waller MW, Spriggs A, Hallfors DD. Adolescent predictors of emerging adult sexual patterns. Journal of Adolescent Health. 2006; 39(6):926.e910-926.e921. [PubMed: 17116527]

Hamilton BE, Martin JA, Ventura SJ. Births: preliminary data for 2010. National Vital Statistics Reports. 2011; 60(2)

Harris, KM. Design features of add health. Carolina Population Center: University of North Carolina at Chapel Hill; 2011. http://www.cpc.unc.edu/projects/addhealth/data/guides/design\%20paper $\%$ 20WI-IV.pdf

Hofferth SL, Reid L. Early childbearing and children's achievement and behavior over time. Perspectives on Sexual and Reproductive Health. 2002:41-49. [PubMed: 11990638]

Hoffman, SD.; Maynard, RA. Kids having kids: Economic costs and social consequences of teen pregnancy. Washington: DC: The Urban Institute Press; 2008.

IOM. Progress in preventing childhood obesity: Focus on industry-brief summary. Washington, D.C: Institute of ME, National Academy Press; 2006.

Jones EF, Forrest JD. Underreporting of abortion in surveys of US women: 1976 to 1988. Demography. 1992; 29(1):113-126. [PubMed: 1547898]

Kreager DA, Haynie DL. Dangerous liaisons? Dating and drinking diffusion in adolescent peer networks. American Sociological Review. 2011; 76(5):737-763.

Kreft, I.; De Leeuw, J. Introducing multilevel modeling. Thousand Oaks, CA: Sage; 1998.

Metwally M, Li TC, Ledger WL. The impact of obesity on female reproductive function. Obesity Reviews. 2007; 8(6):515-523. [PubMed: 17868286]

Mueller AS, Pearson J, Muller C, Frank K, Turner A. Sizing up peers: adolescent girls' weight control and social comparison in the school context results ofa factorial priming experiment. Journal of Health and Social Behavior. 2010; 51(1):64-78. [PubMed: 20420295]

Needham BL, Crosnoe R. Overweight status and depressive symptoms during adolescence. Journal of Adolescent Health. 2005; 36(1):48-55. [PubMed: 15661596] 
Ogden, CL.; Carroll, MD. Prevalence of obesity among children and adolescents: United States, trends 1963-1965 through 2007-2008. NCHS Health E-Stats: 2010.

Ogden CL, Carroll MD, Curtin LR, Lamb MM, Flegal KM. Prevalence of high body mass index in US children and adolescents, 2007-2008. JAMA: The Journal of the American Medical Association. 2010; 303(3):242-249. [PubMed: 20071470]

Ogden CL, Carroll MD, Kit BK, Flegal KM. Prevalence of obesity and trends in body mass index among US children and adolescents, 1999-2010. JAMA: The Journal of the American Medical Association. 2012; 307(5):483-490. [PubMed: 22253364]

Puhl RM, Latner JD. Stigma, obesity, and the health of the nation's children. Psychological Bulletin. 2007; 133(4):557. [PubMed: 17592956]

Ratcliff MB, Jenkins TM, Reiter-Purtill J, Noll JG, Zeller MH. Risk-taking behaviors of adolescents with extreme obesity: normative or not? Pediatrics. 2011; 127(5):827-834. [PubMed: 21518723]

Raudenbush, SW.; Bryk, AS. Hierarchical linear models: Applications and data analysis methods. Vol. Vol. 1. Sage Publications, Inc: 2002.

Schoen R, Landale NS, Daniels K. Family transitions in young adulthood. Demography. 2007; 44(4): 807-820. [PubMed: 18232212]

Singh S, Darroch JE. Adolescent pregnancy and childbearing: levels and trends in developed countries. Family Planning Perspectives. 2000:14-23. [PubMed: 10710702]

Snyder, TD.; Dillow, SA. Digest of education statistics: 2010 (NCES 2011-015). Washington, DC: Institute for Education Statistics: National Center for Education Statistics; 2011.

Steward NR, Farkas G, Bingenheimer JB. Detailed educational pathways among females after very early sexual intercourse. Perspectives on Sexual and Reproductive Health. 2009; 41(4):244-252. [PubMed: 20444180]

Teitler JO, Weiss CC. Effects of neighborhood and school environments on transitions to first sexual intercourse. Sociology of Education. 2000:112-132.

Upchurch DM, Lillard LA, Aneshensel CS, Li NF. Inconsistencies in reporting the occurrence and timing of first intercourse among adolescents. The Journal of Sex Research. 2002:197-206.

Villers, MS.; Swanson, EM.; Savage, AH.; Korte, JF. Sexual behavior in obese and overweight adolescent females; Paper presented at the American Congress of Obstetrics and Gynecologists (ACOG) 58th Annual Clinical Meeting; San Francisco, CA. 2010.

Wingood GM, DiClemente RJ, Harrington K, Davies SL. Body image and African American females' sexual health. Journal of Women's Health \& Gender-based Medicine. 2002; 11(5):433-439. 


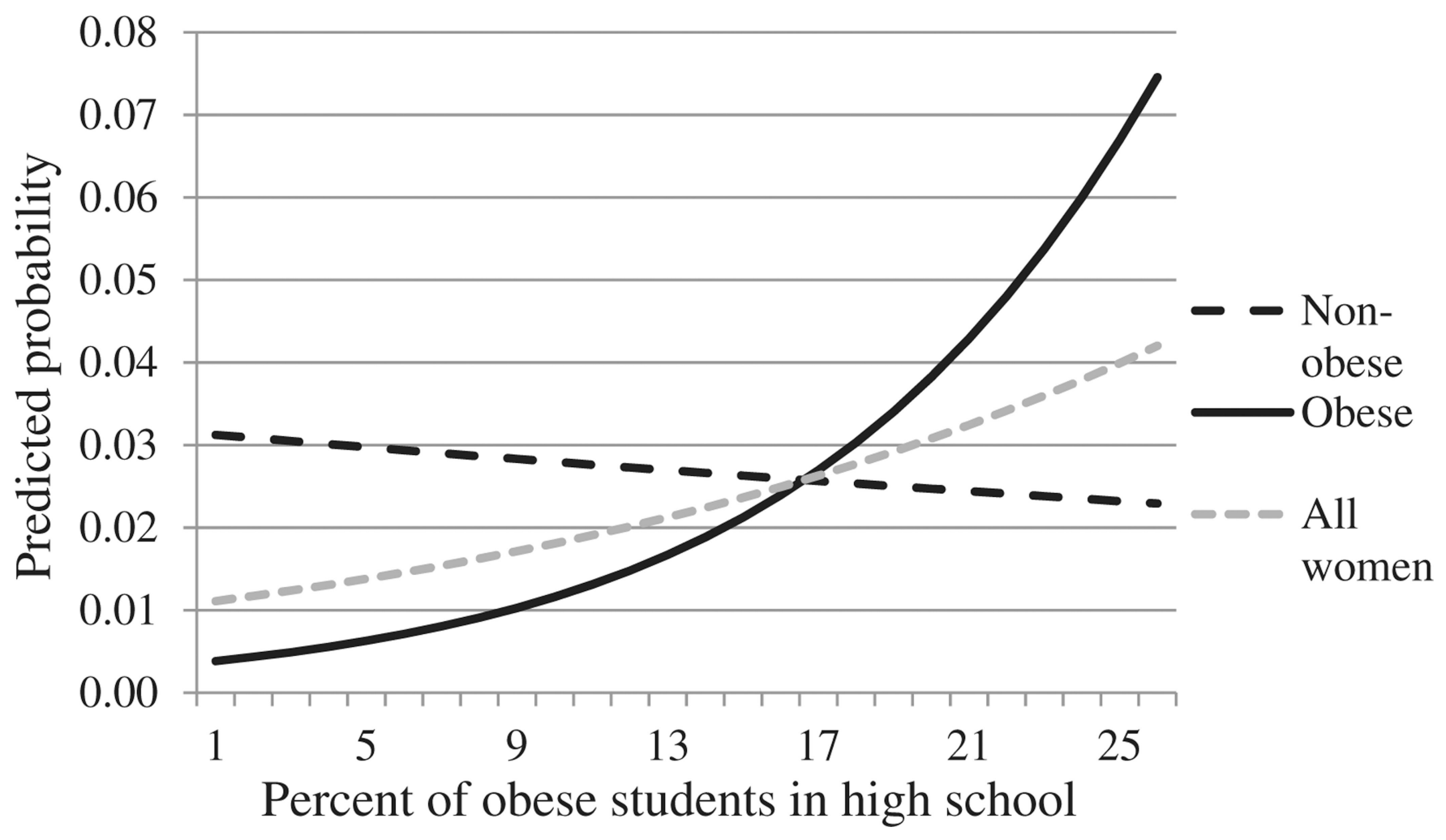

Fig. 1.

Predicted probability of childbearing for obese and non-obese high school young women, as the proportion of obese students in a school increases.

Notes: The proportion of students who are obese in any given high school does extend beyond $26.3 \%$. The graph reflects this by truncating the predicted probability of childbearing across this range. Thus, estimates do not extrapolate beyond what is real in our data. 
Table 1

Descriptive characteristics of a subsample of female high school students and the schools they attend.

\begin{tabular}{|c|c|}
\hline & $\%$ or mean \\
\hline \multicolumn{2}{|l|}{ Panel A. Total Sample of Individuals $(N=4242)$} \\
\hline High school childbearing $(\%)$ & 4.9 \\
\hline Obese $(\%)$ & 9.4 \\
\hline \multicolumn{2}{|l|}{ Sociodemographic characteristics } \\
\hline \multicolumn{2}{|l|}{ Race/ethnicity } \\
\hline Non-Hispanic Black (\%) & 16.0 \\
\hline Hispanic $(\%)$ & 19.6 \\
\hline Non-Hispanic Other $(\%)$ & 6.0 \\
\hline Non-Hispanic White (\%) (reference) & 58.5 \\
\hline Single mother household $(\%)$ & 18.8 \\
\hline Parent(s) did not complete high school (\%) & 18.7 \\
\hline Mean household income-needs ratio (range, $0-83.7$ ) & $3.1(0.18)$ \\
\hline Mean age (range, 13-21) & $16.3(0.04)$ \\
\hline \multicolumn{2}{|l|}{ Other individual-level control variables } \\
\hline Sexual initiator $(\%)$ & 39.8 \\
\hline Mean number of sexual partners (range, $0-4$ ) & $0.8(0.05)$ \\
\hline Mean age at first menses (range, 7-26) & $12.7(0.06)$ \\
\hline Mean self-esteem (range, 1-5) & $4.0(0.02)$ \\
\hline \multicolumn{2}{|l|}{ Weight perceptions } \\
\hline Underweight (\%) & 11.4 \\
\hline Overweight (\%) & 39.8 \\
\hline Just about the right weight (\%) (reference) & 48.8 \\
\hline Mean interviewer-rated physical attractiveness (range, 1-5) & $3.7(0.03)$ \\
\hline Dropped or stopped out of high school (\%) & 10.5 \\
\hline \multicolumn{2}{|l|}{ Panel B. Total Sample of Schools $(N=102)$} \\
\hline Proportion of obese students in school (range, 1.5-26.3) & $10.7(0.50)$ \\
\hline Average income-needs ratio (range, 1.3-9.5) & $2.8(0.14)$ \\
\hline \multicolumn{2}{|l|}{ Racial composition } \\
\hline Proportion non-Hispanic Black (range, 0-99.2) & $25.3(0.03)$ \\
\hline Proportion Hispanic (range, 0-89.6) & $8.8(0.03)$ \\
\hline Proportion non-Hispanic other (range, 0-69.1) & $4.0(0.01)$ \\
\hline Proportion non-Hispanic White (range, $0-100$ ) & $62.0(0.04)$ \\
\hline \multicolumn{2}{|l|}{ School urbanicity } \\
\hline Suburban $(\%)$ & 52.9 \\
\hline Rural (\%) & 24.1 \\
\hline Urban $(\%)$ (reference) & 23.0 \\
\hline \multicolumn{2}{|l|}{ Region } \\
\hline West (\%) & 17.7 \\
\hline Midwest (\%) & 29.7 \\
\hline
\end{tabular}




\begin{tabular}{cl}
\hline & \% or mean \\
\hline South $(\%)$ & 39.6 \\
Northeast (\%) (reference) & 13.0 \\
Percent of students testing below grade level (range, 0-9.9) & $2.7(0.71)$ \\
Mean grade point average (range, 2.3-4.1) & $3.0(0.03)$ \\
Proportion students participating in a sport (range, 29.1-94.3) & $63.3(0.02)$ \\
\hline
\end{tabular}

Notes: Figures are weighted. Standard errors for means are in shown in parentheses. 


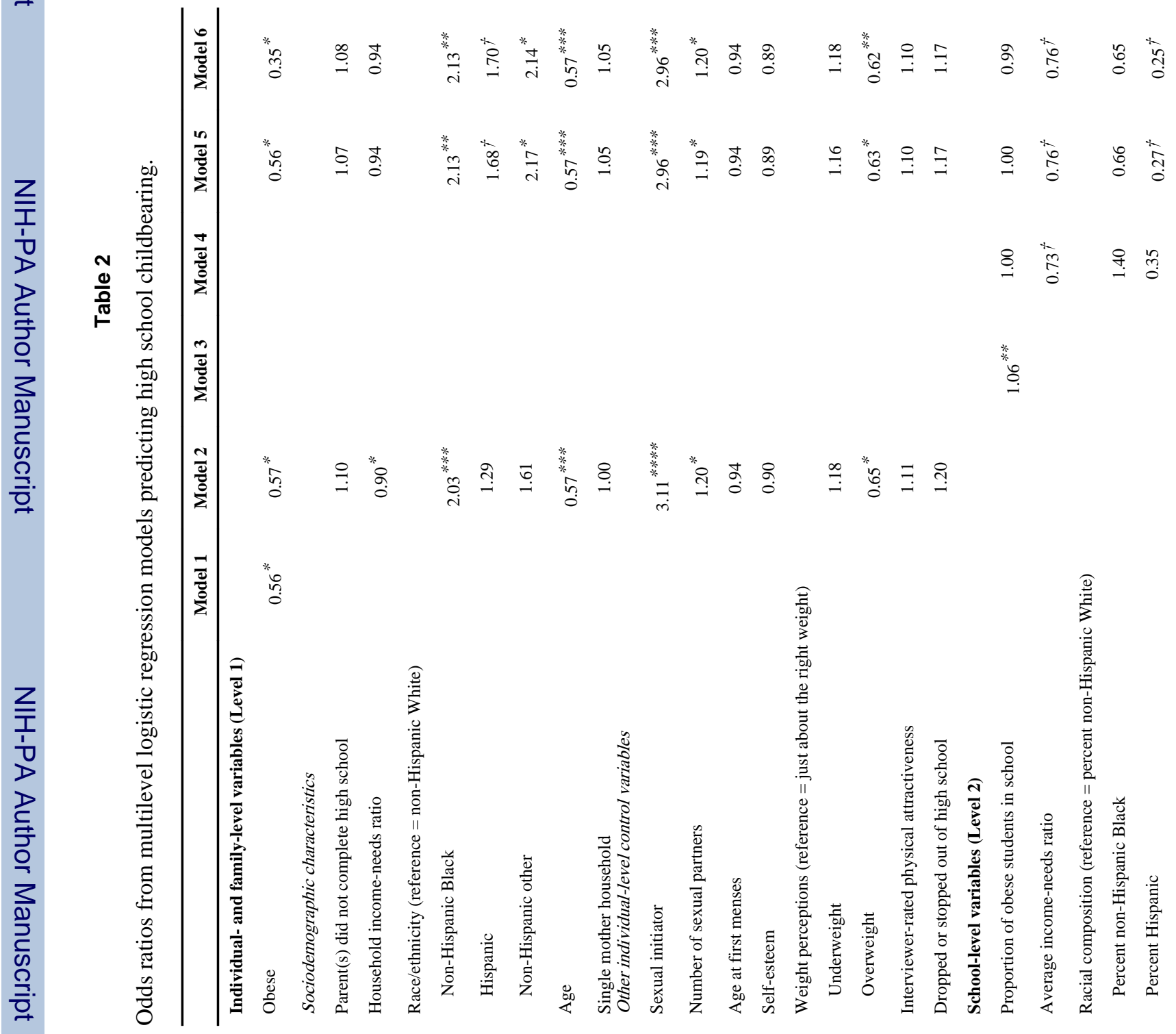




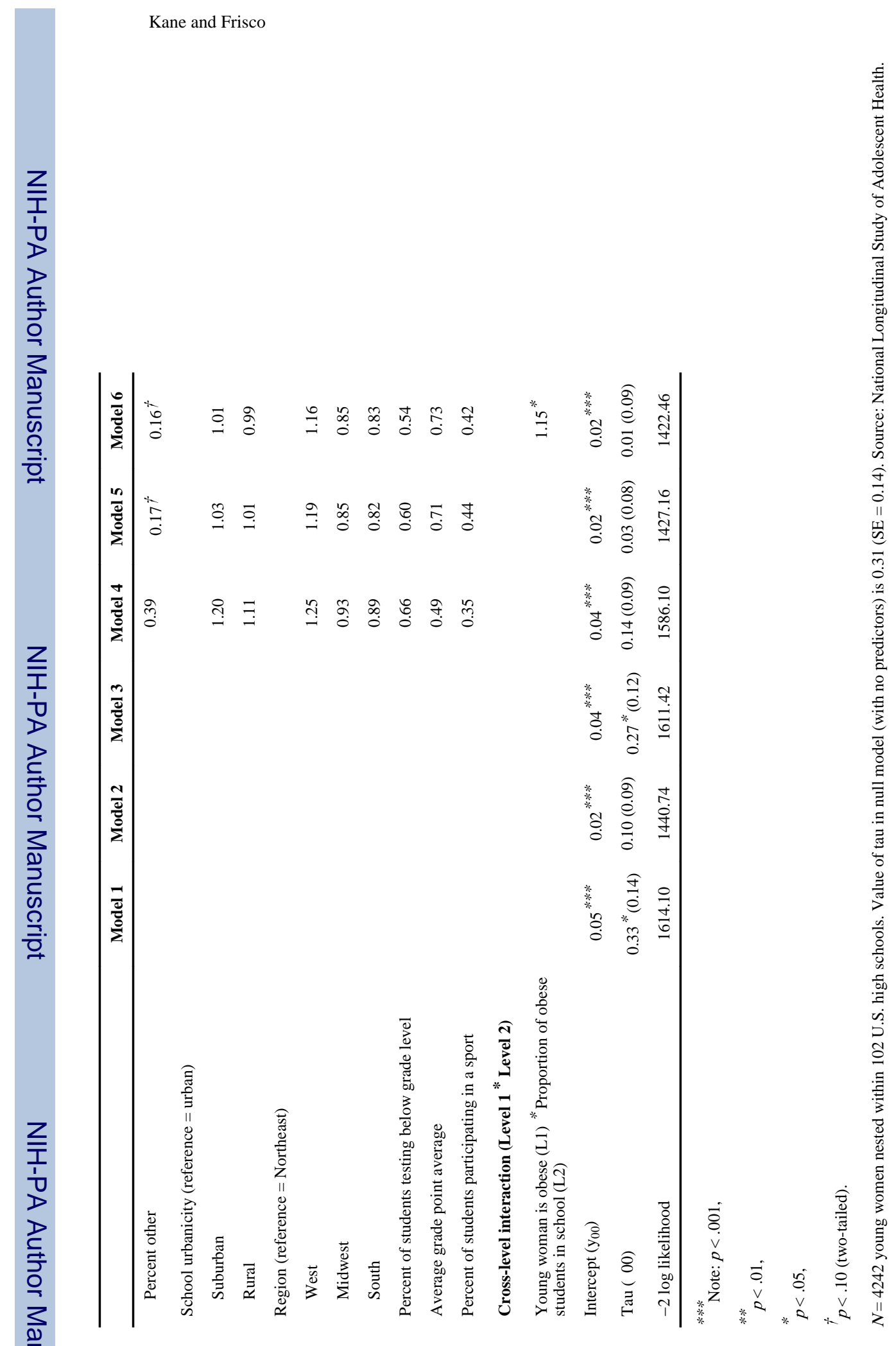

Soc Sci Med. Author manuscript; available in PMC 2014 July 01. 